\title{
The effect of exercise training on clinical outcomes in patients with the metabolic syndrome: a systematic review and meta-analysis
}

\author{
C. Ostman ${ }^{1}$, N. A. Smart ${ }^{2}$, D. Morcos ${ }^{1}$, A. Duller ${ }^{1}$, W. Ridley ${ }^{1}$ and D. Jewiss ${ }^{1}$
}

\begin{abstract}
Background: Purpose: to establish if exercise training improves clinical outcomes in people with metabolic syndrome (MetS). Registered with PROSPERO international prospective register of systematic reviews (https://www.crd.york. ac.uk/PROSPERO/Identifier:CRD42017055491). Data sources: studies were identified through a MEDLINE search strategy (1985 to Jan 12, 2017), Cochrane controlled trials registry, CINAHL and SPORTDiscus. Study selection: prospective randomized or controlled trials of exercise training in humans with metabolic syndrome, lasting 12 weeks or more.

Results: We included 16 studies with 23 intervention groups; 77,000 patient-hours of exercise training. In analyses of aerobic exercise studies versus control: body mass index was significantly reduced, mean difference (MD) -0.29 $\left(\mathrm{kg} \mathrm{m}^{-2}\right)(95 \% \mathrm{Cl}-0.44,-0.15, \mathrm{p}<0.0001)$; body mass was significantly reduced, $\mathrm{MD}-1.16 \mathrm{~kg}(95 \% \mathrm{Cl}-1.83,-0.48$, $\mathrm{p}=0.0008)$; waist circumference was significantly reduced $\mathrm{MD}-1.37 \mathrm{~cm}(95 \% \mathrm{Cl}-2.02,-0.71, \mathrm{p}<0.0001)$, peak $\mathrm{VO}_{2}$ was significantly improved $\mathrm{MD} 3.00 \mathrm{~mL} \mathrm{~kg}^{-1} \mathrm{~min}^{-1}(95 \% \mathrm{Cl} 1.92,4.08, \mathrm{p}<0.000001)$; systolic blood pressure and diastolic blood pressure were significantly reduced, $\mathrm{MD}-2.54 \mathrm{mmHg}(95 \% \mathrm{Cl}-4.34,-0.75, \mathrm{p}=0.006)$, and, $\mathrm{MD}$ $-2.27 \mathrm{mmHg}(95 \% \mathrm{Cl}-3.47,-1.06, \mathrm{p}=0.0002)$ respectively; fasting blood glucose was significantly reduced $\mathrm{MD}$ $-0.16 \mathrm{mmol} \mathrm{L}^{-1}(95 \% \mathrm{Cl}-0.32,-0.01, \mathrm{p}=0.04)$; triglycerides were significantly reduced $\mathrm{MD}-0.21 \mathrm{mmol} \mathrm{L}^{-1}(95 \%$ $\mathrm{Cl}-0.29,-0.13, \mathrm{p}<0.00001)$; and low density lipoprotein was significantly reduced $\mathrm{MD}-0.03 \mathrm{mmol} \mathrm{L}^{-1}(95 \% \mathrm{Cl}$ $-0.05,-0.00, p=0.02)$. In analyses of combined exercise versus control: waist circumference, $\mathrm{MD}-3.80 \mathrm{~cm}(95 \% \mathrm{Cl}$ $-5.65,-1.95, \mathrm{p}<0.0001$ ); peak $\mathrm{VO}_{2} \mathrm{MD} 4.64 \mathrm{~mL} \mathrm{~kg}^{-1} \mathrm{~min}^{-1}$ (95\% Cl 2.42, 6.87, $\mathrm{p}<0.0001$ ); systolic blood pressure $\mathrm{MD}-3.79 \mathrm{mmHg}(95 \% \mathrm{Cl}-6.18,-1.40, \mathrm{p}=0.002)$; and high density lipoprotein (HDL) MD 0.14 (95\% Cl 0.04, 0.25, $p=0.009$ ) were all significantly improved. We found no significant differences between outcome measures between the two exercise interventions.
\end{abstract}

Conclusions: Exercise training improves body composition, cardiovascular, and, metabolic outcomes in people with metabolic syndrome. For some outcome measures, isolated aerobic exercise appears optimal.

Keywords: Metabolic syndrome, Exercise training, Meta-analysis

\section{Introduction}

According to the international diabetes federation, the metabolic syndrome (MetS) is characterised by at least three of five clinical findings: central obesity, elevated

\footnotetext{
*Correspondence: nsmart2@une.edu.au

${ }^{2}$ School of Science and Technology, University of New England, Armidale, NSW 2351, Australia

Full list of author information is available at the end of the article
}

blood pressure (systolic blood pressure $\geq 130 \mathrm{mmHg}$ or diastolic blood pressure $\geq 85 \mathrm{mmHg}$ ), elevated serum triglycerides $\left(\geq 150 \mathrm{mg} \mathrm{dL}^{-1}\right)$, low serum high-density lipoprotein (HDL) $\left(<40 \mathrm{mg} \mathrm{dL}^{-1}\right.$ in males and $<50 \mathrm{mg} \mathrm{dL}^{-1}$ in females), and insulin resistance (fasting plasma glucose $\geq 100 \mathrm{mg} \mathrm{dL}^{-1}$ ) [1]. More than $20 \%$ of the world's population is estimated to meet the diagnostic criteria for MetS, and are thus three times more likely to develop 
cardiovascular disease and five times more likely to develop type 2 diabetes, presenting an enormous public health issue [2].

Previous data pooling analyses are yet to show a wide scope of benefit from exercise training in people with metabolic syndrome. Analyses of lifestyle interventions are yet to show a reduction in the proportion of participants who meet the diagnostic criteria for MetS [3], although summary data are available outlining significant improvements in both body composition and metabolic profile measures with lifestyle intervention in women with metabolic derangement due to polycystic ovarian syndrome [4, 5]. Lifestyle (diet and exercise) has been shown to be effective in resolving MetS and reducing the severity of related abnormalities (fasting blood glucose, waist circumference, systolic blood pressure and diastolic blood pressure, and triglycerides) [3]. While the beneficial clinical effects of lifestyle interventions have been shown in meta-analyses of participants with type II diabetes [6], the relative contribution of exercise, in deriving these benefits, is unknown. Resistance training interventions of patients with MetS has been found to reduce systolic blood pressure, but not fasting plasma glucose, HDL cholesterol, triglycerides, diastolic blood pressure, or waist circumference [7]. It is however possible that the small number of included studies precluded significant improvements in other outcome relevant measures. The meta-analysis by Aguilera et al. [8] was unable to uncover enough evidence (only one study yielded eligible data) to draw meaningful conclusions around the optimal exercise intensity to treat metabolic syndrome. The work of Lin et al. [9] reported beneficial effects of exercise training on cardiac risk factors, but this work included studies of both healthy people and those with metabolic disease. It remains unclear which type of exercise, and at what intensity, is optimal for patients.

We therefore conducted a systematic analysis of all clinical randomized, controlled, exercise training trials in patients with MetS and stratified the trials by exercise intensity according to recognized guidelines. We aimed to determine whether high-intensity exercise produced different effect sizes for change in clinical outcomes in MetS compared to vigorous-, moderate- and low-intensity training and sedentary lifestyle. We also wished to establish whether the effect on clinical outcomes in MetS varied according to the type of intervention (aerobic versus combined aerobic and resistance training).

\section{Methods}

The review protocol was registered in PROSPERO international prospective register of systematic reviews (https://www.crd.york.ac.uk/PROSPERO/Identifier: CRD42017055491).

\section{Data sources and search strategy}

Studies were identified through a MEDLINE search strategy (1985 to Jan 12, 2017), Cochrane controlled trials registry (1966 to Jan 12, 2017), CINAHL, SPORTDiscus and science citation index. The search strategy included a mix of $\mathrm{MeSH}$ and free text terms for key concepts related to exercise training and the metabolic syndrome (see PubMed search strategy in Additional file 1). Studies were included if patients in the intervention group met the diagnostic criteria for metabolic syndrome (according to IDF, WHO, or NCEP-ATP III) [1]. Searches were limited to prospective randomized or controlled trials of exercise training in humans. Only English language studies were included. No restrictions were placed on the year of publication. Reference lists of papers were scrutinised for new articles. Full articles were read and assessed by two reviewers (CO and DJ) for relevance and study eligibility. Disagreements on methodology were resolved by discussion, and a third reviewer (NS) adjudicated over any disputes. Study authors were contacted and requested to provide further data if required.

\section{Study selection}

Included studies were randomized controlled trials of exercise training in people with the metabolic syndrome diagnosed according to recognized diagnostic criteria (IFD, WHO, or NCEP-ATP III) [1]. All published studies included in this systematic review were comparisons between intervention groups and a sedentary control. After initial screening, we removed over-lapping and duplicate articles, as well as articles that did not meet inclusion criteria. We excluded studies whereby not all participants in the intervention group met the diagnostic criteria for metabolic syndrome at the start of the intervention, studies that did not have a sedentary control group, and those reporting only acute exercise testing responses. Studies with diet or medical interventions were included only if the intervention was constant across the exercise and control groups (Table 1). Only the principal study with the greatest number of subjects was included where multiple publications existed from the same dataset. We excluded data from specific analysis if incomplete data was reported and the authors did not respond to our requests to provide missing data.

\section{Outcome measures}

We recorded the following data: incident mortality and hospitalisation. We also recorded change in (baseline versus post intervention): peak $\mathrm{VO}_{2}, \mathrm{BMI}$, body weight, waist circumference, systolic blood pressure, diastolic blood pressure, fasting blood glucose, fasting insulin, HOMA-IR, HbA1c\%, HDL, LDL, TG, and, total cholesterol. We also recorded exercise training frequency, 


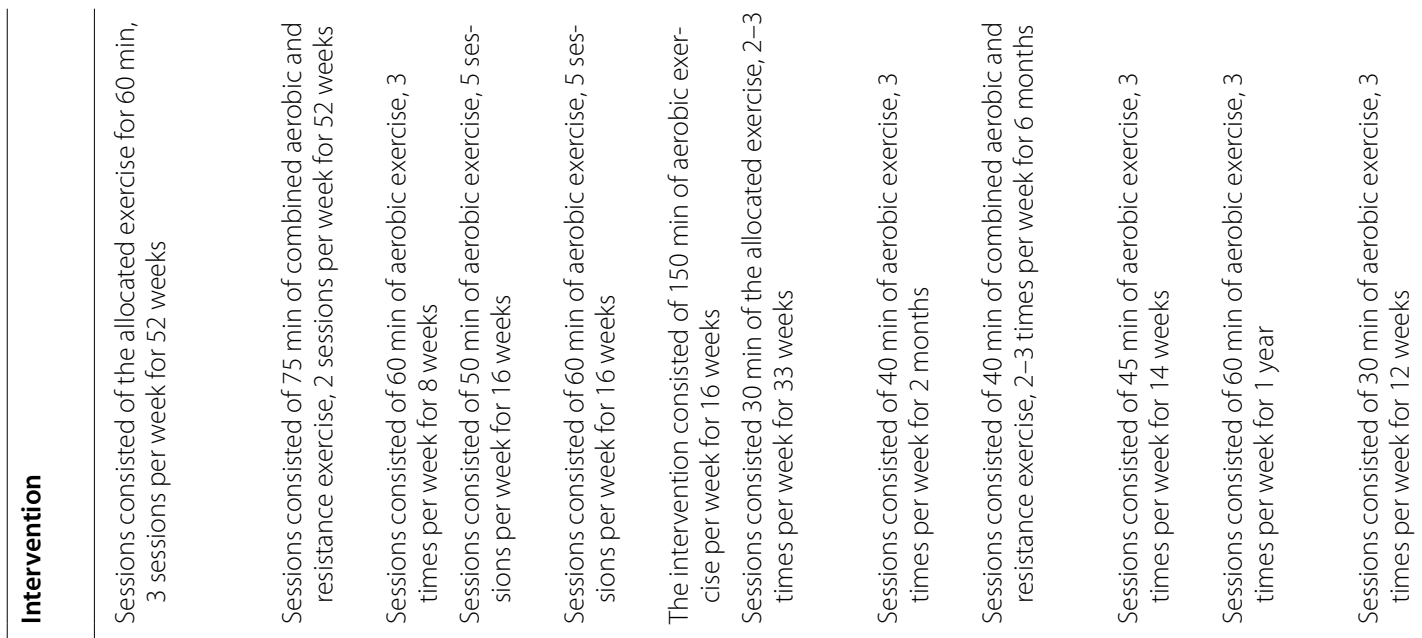

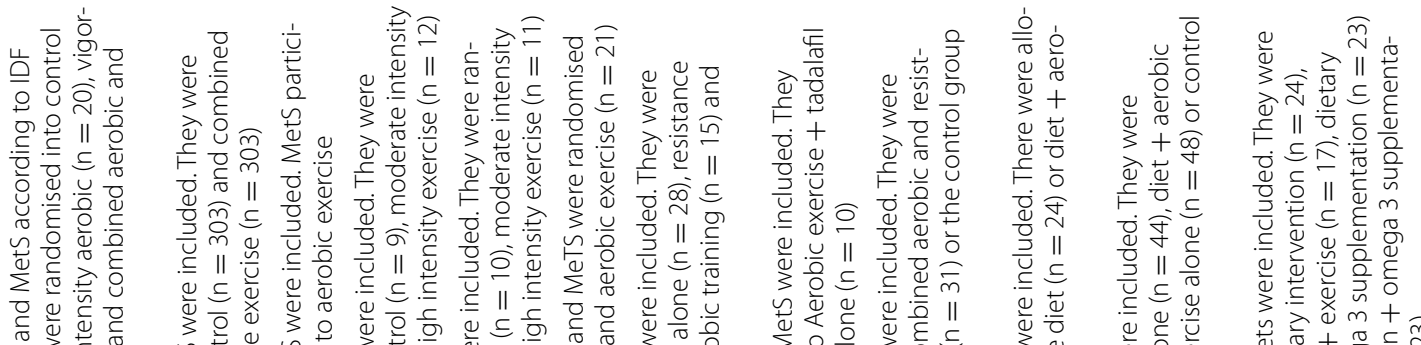

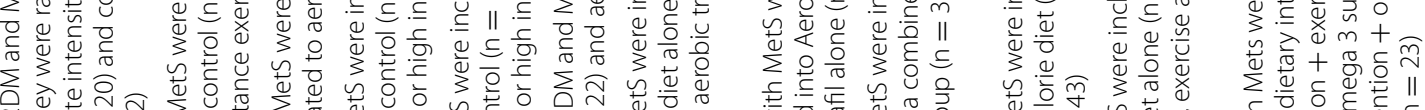

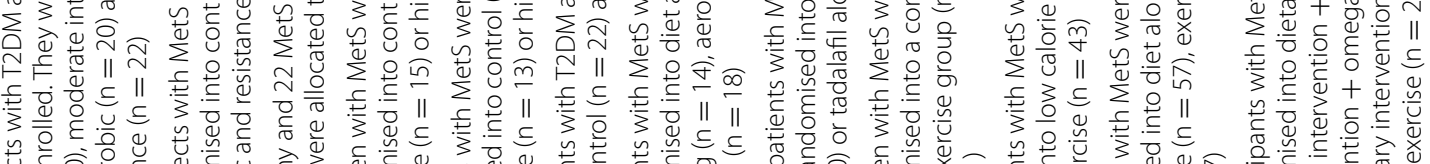

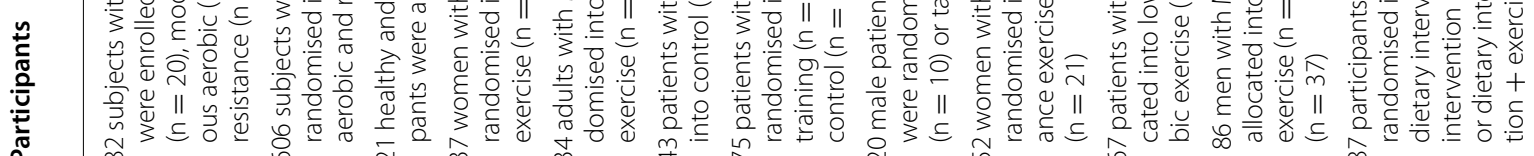

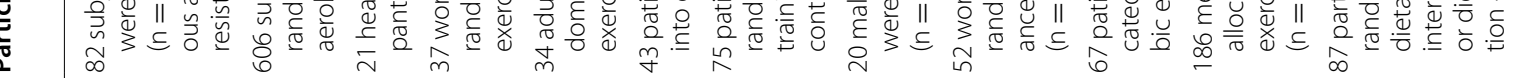




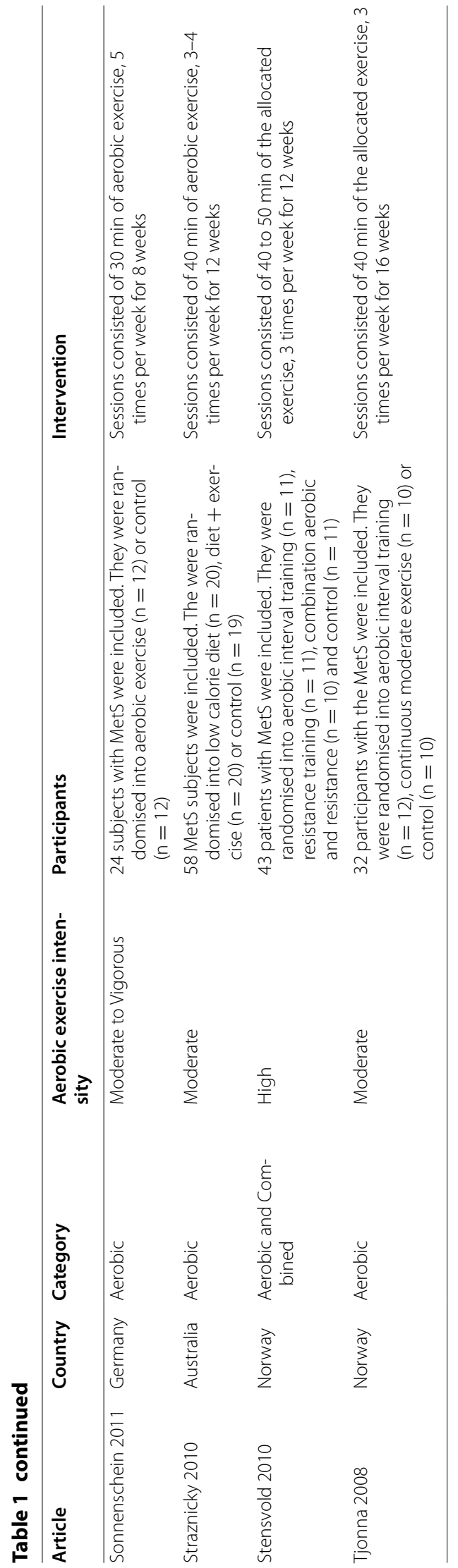


intensity, duration per-session, length of exercise programs and concurrent interventions e.g. diet.

\section{Data synthesis}

From extracted data, we calculated patient-hours of exercise training, mean difference change in outcome measures, drop out and attendance rates, and medical events.

\section{Assessment of study quality}

We assessed study quality with regards to: eligibility criteria specified, random allocation of participants, allocation concealed, similarity of groups at baseline, assessors blinded, outcome measures assessed in $85 \%$ of participants and intention to treat analysis. The study quality was assessed according to the validated TESTex scale which has a maximum score of 15 [10].

\section{Data analysis}

Revman 5.3 (Nordic Cochrane Centre, Denmark) was used to complete the meta-analysis and generate forest plots. Pooled data are presented as mean differences. We chose a random effects model as an element of randomness is inevitable when pooling data from individual studies. A minimum of two studies was required for forest plots. Some studies used more than one intervention group, but the same people were only represented once in our forest plots.

Meta-analyses were completed for continuous data by using the change in the mean and standard deviation of outcome measures. It is an accepted practice to only use post-intervention data for meta-analysis but this method assumes that random allocation of participants always creates intervention groups matched at baseline for age, disease severity, etc. Change in post intervention mean was calculated by subtracting baseline from postintervention values [11]. Data required was either: (i) $95 \%$ confidence interval data for pre- and post-intervention change for each group, or when this was unavailable; (ii) actual $\mathrm{p}$ values for pre- and post-intervention change for each group, or if only the level of statistical significance was available; (iii) we used default $\mathrm{p}$ values, e.g. $\mathrm{p}<0.05$ becomes $\mathrm{p}=0.049, \mathrm{p}<0.01$ becomes $\mathrm{p}=0.0099$ and $\mathrm{p}=$ not significant becomes $\mathrm{p}=0.05$. If $95 \%$ confidence intervals overlapped between two or more sub-analyses of the same outcome measure, where data was presented as 'MD (95\% CI)', we assumed that there was no statistically significant difference between the groups.

\section{Heterogeneity}

Heterogeneity was quantified using the $\mathrm{I}^{2}$ test, as it does not inherently depend on the number of studies considered [12]. $\mathrm{I}^{2}$ values range from $0 \%$ (homogeneous) to $100 \%$ (greater heterogeneity); a CI that does not include $0 \%$ indicates that the hypothesis of homogeneity is rejected, and an inference of heterogeneity is merited. We used a random effects model for all analyses.

\section{Publication bias}

Funnel plots were examined for evidence of publication bias [13].

\section{Results}

Records were initially identified through database searching and additional records from the reference list were added. Only the principal study with the greatest subjects was included where multiple publications existed from the same dataset. After initial screening of titles, irrelevant studies were removed, which include over-lapping studies, abstracts, and irrelevant articles, such as editorials and discussion papers that did not match the inclusion criteria. Forty-five duplicate papers were identified and removed. We excluded a further 32 studies with reasons: 12 studies due to study design, two due to the article being in Spanish, four did not have an aerobic intervention and 14 had insufficient or irrelevant data for inclusion in the meta-analysis (see consort statement, Fig. 1).

The 16 included studies [14-26] produced 23 intervention groups (See Table 1). There were 14 studies that had intervention groups that compared aerobic exercise versus sedentary control and four studies that had intervention groups that compared a combined aerobic and resistance exercise versus sedentary control. Overall, the 16 studies provided more than 800 exercising participants which resulted in more than 77,000 patient-hours of exercise training.

\section{Comparison of all aerobic exercise studies versus control Body composition outcome measures}

BMI was significantly reduced by a mean difference (MD) of $-0.29\left(\mathrm{~kg} \mathrm{~m}^{-2}\right)(95 \% \mathrm{CI}-0.44,-0.15, \mathrm{p}<0.0001)$ in exercise versus control groups. Body mass was significantly reduced by a mean difference of $-1.16 \mathrm{~kg}$ (95\% $\mathrm{CI}-1.83,-0.48, \mathrm{p}=0.0008)$ in exercise versus control groups. Waist circumference was significantly reduced by $-1.37 \mathrm{~cm}(95 \% \mathrm{CI}-2.02,-0.71, \mathrm{p}<0.0001)$ in exercise versus control groups (Table 2). Total body fat mass was significantly reduced MD $-1.19 \mathrm{~kg}(95 \% \mathrm{CI}-1.79$, $-0.59, \mathrm{p}=0.0001)$ in exercise versus control.

\section{Cardiovascular outcome measures}

Peak $\mathrm{VO}_{2}$ was significantly improved, MD $3.00 \mathrm{ml} \mathrm{kg}^{-1} \mathrm{~min}^{-1}$ (95\% CI 1.92, 4.08, $\mathrm{p}<0.000001$ ), in exercise versus control groups. Systolic blood pressure was significantly reduced, MD $-2.54 \mathrm{mmHg}(95 \% \mathrm{CI}$ $-4.34,-0.75, \mathrm{p}=0.006$ ), as was diastolic blood pressure, 


\section{Articles identified through database and reference searching $(n=588)$}

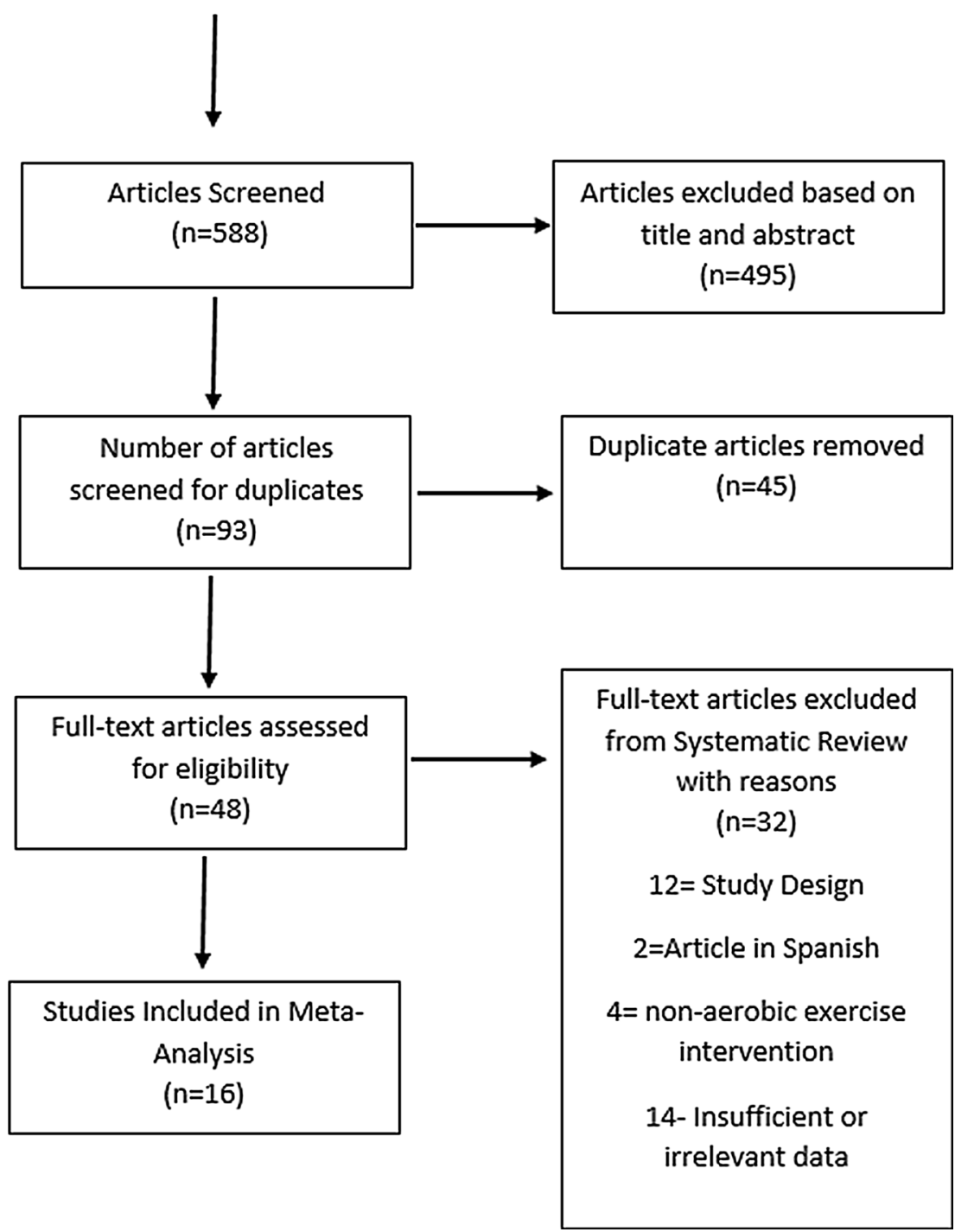

Fig. 1 Consort statement

MD $-2.27 \mathrm{mmHg}(95 \% \mathrm{CI}-3.47,-1.06, \mathrm{p}=0.0002)$, in exercise compared to control groups (Table 2).

\section{Metabolic outcome measures}

Fasting blood glucose was significantly reduced, MD $-0.16 \mathrm{mmol} \mathrm{L}^{-1}$ (95\% CI $\left.-0.32,-0.01, \mathrm{p}=0.04\right)$, in exercise compared to control groups. Triglycerides were significantly improved MD $-0.21 \mathrm{mmol} \mathrm{L}^{-1}$ (95\% CI $-0.29,-0.13, \mathrm{p}<0.00001)$; and LDL cholesterol was significantly improved MD $-0.03 \mathrm{mmol} \mathrm{L}^{-1}$ (95\% CI -0.05,
$-0.00, \mathrm{p}=0.02)$ in exercise versus control participants. HDL cholesterol was unchanged in exercise versus control participants (Table 2).

\section{Combined aerobic and resistance exercise versus control} In the comparison of combined exercise versus control participants only: waist circumference, $\mathrm{MD}-3.80 \mathrm{~cm}$ (95\% CI $-5.65,-1.95, \mathrm{p}<0.0001)$; peak $\mathrm{VO}_{2}, \mathrm{MD}$ $4.64 \mathrm{ml} . \mathrm{kg}^{-1} \mathrm{~min}^{-1}$ (95\% CI 2.42, 6.87, $\left.\mathrm{p}<0.0001\right)$; systolic blood pressure, $\mathrm{MD}-3.79 \mathrm{mmHg}(-6.18,-1.40$, 
Table 2 Effect of different exercise training programs on MetS

\begin{tabular}{|c|c|c|c|c|c|c|c|c|}
\hline \multirow[t]{2}{*}{ Outcome } & \multicolumn{4}{|c|}{ Aerobic exercise versus control } & \multicolumn{4}{|c|}{$\begin{array}{l}\text { Combined aerobic and resistance exercise versus con- } \\
\text { trol }\end{array}$} \\
\hline & No. studies & $\mathbf{N}$ & $\mathrm{MD}(95 \% \mathrm{Cl}), \mathrm{p}$ value & $I^{2}(\%)$ & No. studies & $\mathrm{N}$ & $\mathrm{MD}(95 \% \mathrm{Cl}), \mathrm{p}$ value & $I^{2}$ \\
\hline BMI $\left(\mathrm{kg} \mathrm{m}^{-2}\right)$ & 14 & 385 & $-0.29(-0.44,-0.15) p<0.0001$ & 79 & 3 & 652 & $-0.40(-0.88,0.07) p=0.10$ & $100 \%$ \\
\hline Body weight (kg) & 11 & 217 & $-1.16(-1.83,-0.48) p=0.0008$ & 43 & 2 & 46 & $-0.03(-0.51,0.46) p=0.92$ & $24 \%$ \\
\hline Waist $(\mathrm{cm})$ & 13 & 261 & $-1.37(-2.02,-0.71) p<0.0001$ & 61 & 3 & 652 & $-3.80(-5.65,-1.95) p<0.0001$ & $59 \%$ \\
\hline Total fat mass $(\mathrm{kg})$ & 5 & 176 & $-1.19 \mathrm{~kg}(-1.79,-0.59)=0.0001$ & 0 & 0 & 0 & N/A & N/A \\
\hline Peak VO$O_{2}\left(\mathrm{~mL} \mathrm{~kg}^{-1} \mathrm{~min}^{-1}\right)$ & 13 & 294 & $3.00(1.92,4.08) p<0.000001$ & 60 & 3 & 652 & $4.64(2.42,6.87) p<0.0001$ & $48 \%$ \\
\hline $\mathrm{SBP}(\mathrm{mmHg})$ & 15 & 364 & $-2.54(-4.34,-0.75) p=0.006$ & 78 & 3 & 652 & $-3.79(-6.18,-1.40, p=0.002)$ & $0 \%$ \\
\hline $\mathrm{DBP}(\mathrm{mmHg})$ & 14 & 337 & $-2.27(-3.47,-1.06) p=0.0002$ & 61 & 3 & 652 & $-0.23(-3.53,1.55) p=0.85$ & $68 \%$ \\
\hline $\mathrm{FBG}\left(\mathrm{mmol} \mathrm{L} \mathrm{L}^{-1}\right)$ & 15 & 378 & $-0.16(-0.32,-0.01) p=0.04$ & 81 & 2 & 623 & $-0.18(-0.47,0.25) p=0.21$ & $0 \%$ \\
\hline $\mathrm{HDL}\left(\mathrm{mmol} \mathrm{L}{ }^{-1}\right)$ & 15 & 265 & $0.03(-0.01,0.08) p=0.19$ & 71 & 2 & 623 & $0.14(0.04,0.25) p=0.009$ & $61 \%$ \\
\hline $\mathrm{TG}\left(\mathrm{mmol} \mathrm{L}{ }^{-1}\right)$ & 13 & 308 & $-0.21(-0.29,-0.13) p<0.00001$ & 57 & 1 & 606 & $-0.01(-0.04,0.02) p=0.50$ & $0 \%$ \\
\hline $\mathrm{LDL}\left(\mathrm{mmol} \mathrm{L}{ }^{-1}\right)$ & 2 & 44 & $-0.03(-0.05,-0.00) p=0.02$ & 0 & 1 & 722 & $-0.30(-0.61,0.01) p=0.06$ & $0 \%$ \\
\hline
\end{tabular}

$N$ number of people included in analysis, $B M I$ body mass index, peak $V_{2}$ peak oxygen consumption, $F B G$ fasting blood glucose, $S B P$ systolic blood pressure, $D B P$ diastolic blood pressure, $F B G$ fasting blood glucose, $H D L$ high density lipoproteins, $T G$ triglycerides, $L D L$ low density lipoproteins

$\mathrm{p}=0.002)$; and, HDL cholesterol, MD $0.14 \mathrm{mmol} \mathrm{L}^{-1}$ (95\% CI 0.04, 0.25, $\mathrm{p}=0.009$ ) were significantly changed in combined exercise versus control groups (Table 2). We did not find any statistically significant benefit of combined exercise over aerobic exercise.

\section{Comparison of outcome measures according to exercise intensity and type Body composition outcome measures}

For the analyses of BMI, body mass, total fat mass and waist circumference, we found no statistical difference between moderate, vigorous and high intensity aerobic exercise. The same was true of combined exercise in regards to exercise intensity (Table 3 ).

\section{Cardiovascular outcome measures}

Change in peak $\mathrm{VO}_{2}$ was highest with high intensity aerobic exercise, MD $5.50 \mathrm{~mL} \mathrm{~kg}^{-1} \mathrm{~min}^{-1}$, and combined exercise at moderate intensity, MD $4.83 \mathrm{ml} \mathrm{kg}^{-1} \mathrm{~min}^{-1}$. Change in systolic blood pressure was greatest with high intensity aerobic exercise, $\mathrm{MD}-6.40 \mathrm{mmHg}$. The change in diastolic blood pressure was similar across all exercise intensities and types, although only significant in moderate intensity aerobic and high intensity combined exercise (Table 2).

\section{Metabolic outcome measures}

Fasting blood glucose was only significantly changed with moderate or high intensity aerobic exercise, but the effect

Table 3 Sub analysis of effect of exercise training on MetS by exercise intensity

\begin{tabular}{|c|c|c|c|c|c|}
\hline & \multicolumn{2}{|l|}{ Moderate } & \multirow{2}{*}{$\begin{array}{l}\text { Vigorous } \\
\text { Aerobic }\end{array}$} & \multicolumn{2}{|l|}{ High } \\
\hline & Aerobic & Combined & & Aerobic & Combined \\
\hline $\mathrm{BMI}\left(\mathrm{kg} \mathrm{m}^{-2}\right)$ & $-0.34^{*}(-0.55,-0.14)$ & $-0.57^{*}(-0.86,-0.27)$ & $-0.23(-0.57,0.1)$ & $-0.5^{*}(-0.86,-0.14)$ & $-0.10^{*}(-0.14,-0.06)$ \\
\hline Waist circum. (cm) & $-0.80^{*}(-1.49,-0.12)$ & $-3.99 *(-4.91,-3.06)$ & $-1.59^{*}(-2.39,-0.79)$ & $-3.00 *(-4.65,-1.35)$ & $-2.40^{*}(-3.83,-0.97)$ \\
\hline Total fat mass $(\mathrm{kg})$ & $-1.03^{*}(-1.69,-0.37)$ & N/A & $-2.50^{*}(-4.97,-0.03)$ & $-1.80(-3.76,0.16)$ & N/A \\
\hline $\mathrm{VO}_{2} \max \left(\mathrm{mL} \mathrm{kg}^{-1} \mathrm{~min}^{-1}\right)$ & $2.52^{*}(0.99,4.40)$ & $4.83^{*}(1.10,8.55)$ & $3.20^{*}(1.71,4.69)$ & $5.5^{*}(1.55,9.45)$ & $4.20^{*}(1.35,7.05)$ \\
\hline $\mathrm{SBP}(\mathrm{mmHg})$ & $-3.64(-9.50,2.22)$ & $-3.35(-7.06,0.37)$ & $-1.33^{*}(-1.88,-0.77)$ & $-6.40^{*}(-11.52,-1.28)$ & $-4.10^{*}(-7.21,-0.99)$ \\
\hline $\mathrm{DBP}(\mathrm{mmHg})$ & $-3.35^{*}(-5.50,-1.19)$ & $-1.68(-3.96,0.60)$ & $-1.27(-2.79,0.25)$ & $-3.40(-6.94,0.14)$ & $1.40^{*}(0.56,2.24)$ \\
\hline $\mathrm{FBG}\left(\mathrm{m} \mathrm{mol} \mathrm{L}{ }^{-1}\right)$ & $-0.41^{*}(-0.70,-0.11)$ & $0.00(-0.45,0.45)$ & $-0.06(-0.21,0.08)$ & $0.20^{*}(0.09,0.31)$ & $-0.30(-0.66,0.06)$ \\
\hline $\mathrm{HDL}\left(\mathrm{m} \mathrm{mol} \mathrm{L}{ }^{-1}\right)$ & $0.06(-0.01,0.13)$ & $0.10^{*}(0.04,0.16)$ & $-0.02(-0.05,0.01)$ & $0.16^{*}(0.07,0.25)$ & $0.21^{*}(0.09,0.33)$ \\
\hline $\mathrm{TG}(\mathrm{m} \mathrm{mol} \mathrm{L}-1)$ & $-0.18^{*}(-0.28,-0.09)$ & $-0.01 *(-0.04,0.02)$ & $-0.25^{*}(-0.42,-0.08)$ & $-0.50 *(-0.94,-0.06)$ & N/A \\
\hline
\end{tabular}

Data is MD $(95 \% \mathrm{Cl})$

$* \mathrm{p}<0.05$

$B M I$ body mass index, $V_{2}$ peak maximal oxygen consumption, $S B P$ systolic blood pressure, $D B P$ diastolic blood pressure, $F B G$ fasting blood glucose, $H D L$ high density lipoprotein cholesterol, TG triglycerides 
size was similar in these two analyses. No differences in effect sizes were observed for any of the lipid measures (Table 2).

\section{Sub-analyses}

We found that the addition or absence of dietary intervention did not significantly affect any outcome measures (see Additional file 1: Table S3). Similarly, we found that neither weekly (see Additional file 1: Table S4) nor total program exercise time (see Additional file 1: Table S5) significantly affected outcome measures. We also found that the inclusion of participants with type II diabetes mellitus who also fit diagnostic criteria for MetS did not significantly affect any of the outcome measures.

\section{Study quantity}

We examined several aspects of study quality of included studies. Median TESTex score was 9 out of 15 (see Additional file 1). The distribution of scores was: 1 study scored 5, 2 studies scored 6, 4 studies scored 7, 4 scored 8, 4 scored 9, 9 scored 10, 3 scored 11, 1 scored 12 and 1 scored 13 . The following study quality indicators were completed in $50 \%$ or fewer of the studies: allocation concealment, assessor blinding, intention to treat analysis, and, activity monitoring of the control group.

\section{Publication bias}

Funnel (Egger) plots of the primary analyses showed mild to moderate evidence of publication bias as more than one-third of the studies fell outside the funnel plot border.

\section{Discussion}

Our analysis is the first to compare the effects of aerobic, and combined aerobic and resistance, exercise on clinical outcome measures in people with metabolic syndrome. Our analysis is also the first to compare exercise at different intensities. Through pooled data analysis, we have shown that aerobic exercise provides a range of improvements in outcomes related to body composition, cardiovascular health and metabolic profile. Although still beneficial, combined aerobic and resistance exercise appears to offer a narrower scope of benefits compared to aerobic activity alone. In terms of exercise intensity, insufficient data exists to generate statistical power to define the optimal training intensity. Assessment of study quality indicated that some aspects of study design could be enhanced for future studies.

\section{Body composition outcome measures}

The change in body mass index with aerobic exercise, while statistically significant, was small and therefore likely to be clinically insignificant. A recent government report on the health burden of obesity from the Australian institute of health and welfare suggests that a change in BMI of 1 unit $\left(1 \mathrm{~kg} \mathrm{~m}^{-2}\right)$, equivalent to $2-3 \mathrm{~kg}$ in most women, or $3-4 \mathrm{~kg}$ in most men, is considered a minimum requirement to observe improvements in relative risk of serious illness [27]. The changes in BMI and body mass observed in this analysis did not reach the required threshold to improve health. BMI does not distinguish between lean and fat mass; it may therefore hide any significant changes observed with exercise training in this population as any decrease in fat mass would be met with an increase in lean mass. However, changes in waist circumference were almost $4 \mathrm{~cm}$ in combined exercise programs, suggesting that this type of exercise prescription may be optimal for reducing central obesity. The work by Willis et al. [28] suggests that an isolated aerobic exercise program is optimal for reducing fat mass and body mass, while a combined program is needed for increasing lean mass in middle-aged, overweight/obese individuals. It is possible that the clinically insignificant effect of the various exercise regimes utilized in the pooled data is due to an increase in lean body mass, given it is likely that the participants in the intervention groups were severely deconditioned.

\section{Cardiovascular outcome measures}

Peak $\mathrm{VO}_{2}$ was significantly improved in both isolated aerobic and combined exercise programs. We could not discern which of these approaches was superior as there was no statistically significant difference between the exercise interventions. The change in peak $\mathrm{VO}_{2}$ in both analyses was greater than 1 MET $\left(3.5 \mathrm{~mL} \mathrm{~kg}^{-1} \mathrm{~min}^{-1}\right)$, which is certainly of clinical significance [29]. Impaired age-predicted peak $\mathrm{VO}_{2}$ has been associated with increased risk of mortality in the general population [30] and in several chronic illnesses [31-33], including diabetes [34]. Metabolic syndrome is often the pre-cursor for diabetes. Our analysis also identified beneficial effects of aerobic exercise on both systolic and diastolic blood pressure, while combined exercise showed a benefit in reducing diastolic blood pressure. Previous work has suggested aerobic exercise may be superior to resistance exercise for eliciting anti-hypertensive effects $[35,36]$.

\section{Metabolic outcome measures}

Our analyses of aerobic, but not combined, exercise training reported small improvements in fasting blood glucose, triglycerides and low density lipoproteins. Combined exercise training elicited small changes in high density lipoprotein cholesterol only. With the exception of triglycerides, which reached a reduction of $13 \%$ of the normal level, none of these changes are likely to have reached clinical significance, however may collectively 
contribute to an overall improved health risk profile when combined with body composition and cardiovascular improvements.

\section{Effect of exercise training intensity}

We found that changes in outcome measures related to body composition were significantly improved for subanalyses of moderate, vigorous and high intensity training. We were unable to find a statistically significant difference between the exercise intensities. With this in mind, we found it difficult to discern is there was a superior exercise intensity (Table 3 ). Previous work has shown high intensity exercise to be optimal for the treatment of metabolic syndrome [37] and in other chronic disease populations [38-40].

\section{Recommendations for optimal exercise prescription}

It is important to note that while we could not find statistical difference between analyses of aerobic exercise versus control and combined exercise versus control, some analyses showed a trend towards a larger effect size for some outcome measures. Specifically changes in waist circumference, Peak $\mathrm{VO}_{2}$ and systolic blood pressure appear to be optimal with combined exercise. In contrast, change in body mass, diastolic blood pressure appear to be optimal with aerobic exercise. Furthermore, neither weekly and total exercise program duration, nor the addition of dietary intervention, appears to show a clear additional benefit from exercise for people with MetS. We must however note that these comparisons were unlikely to yield significantly meaningful findings due to the current paucity of combined exercise training studies in MetS. Our recommendation is that people with MetS should adhere to current diabetes exercise guidelines [41].

\section{Roles of hyperglycemia and obesity}

According to the international diabetes federation, metabolic syndrome is characterised by at least three of five clinical findings [1]. One of these findings is hyperglycemia. So, if this definition of MetS is primarily based on hyperglycemia, then we showed that exercise elicits favourable glycaemic effects. We are, however, unsure if these small changes are clinically meaningful. In contrast, insufficient data currently exists to establish if exercise exerts a favourable effect on insulin resistance, MetS' underlying mechanism. Leading on from this, one of the main controversies surrounding the relative importance of the different clinical findings relates to the role of obesity. Our data show significant improvements in both BMI and waist circumference, but again we are unsure if these small changes are clinically meaningful. Another point of controversy relates to clinical outcomes. Most of the studies included in our analysis were of insufficient duration to warrant an analysis of hospitalizations and mortality. Nevertheless, a recent longitudinal study clearly demonstrated that MetS is independently associated with an increased 20-year all-cause mortality [42]. In addition, MetS and all its components are associated with unfavourable cardiovascular changes such as increased arterial stiffness, coronary calcium, diastolic dysfunction and carotid intima media thickness [43-45].

\section{Study quality}

Median study quality was moderate. Future study designs may be improved by improving assessor blinding, conducting intention to treat analyses and introducing, for the first time methods to monitor physical activity levels in the control group participants. Allocation concealment is notoriously difficult in exercise training studies, as this criterion also scored poorly.

\section{Publication bias}

Our funnel plot analyses indicate there is a good chance that there are one or more unpublished datasets in existence due to negative trial results. While most trial showed improvements in direct and indirect markers of metabolic syndrome, the effect sizes were often small enough to be considered clinically insignificant. Researchers should remember though that while changes in individual outcome measures may be considered small, collectively the changes in the overall outcome measure profile may be clinically meaningful.

\section{Limitations}

As with most exercise training research, the available sample size was small and thus limits the generalizability of our results. A number of participants were using medications during the course of the studies. Enrolment in trials of behavioural modification are known to raise subject awareness of interventions such as meditation, weight loss, dietary restriction etc.

\section{Conclusions}

Exercise training produces beneficial changes in body composition, cardiovascular and metabolic outcomes in people with metabolic syndrome. For some outcome measures, isolated aerobic exercise seems to be optimal.

\section{Additional file}

Additional file 1: Table S1. Excluded randomized controlled trials. Table S2. TESTEX Study Quality Assessment. Table S3. Analysis of the effects of exercise and diet on MetS. Table S4. Sub analysis of effect of exercise training on MetS by weekly exercise training duration (mins). Table S5. Sub-analysis of effects of exercise training on MetS by total exercise program time. 


\section{Authors' contributions}

All authors were involved in the concept and data extraction, DJ, CO and NS performed the data analyses, all author contributed to the manuscript preparation.

\section{Author details}

${ }^{1}$ School of Rural Medicine, University of New England, Armidale, NSW 2351, Australia. ${ }^{2}$ School of Science and Technology, University of New England, Armidale, NSW 2351, Australia.

\section{Acknowledgements}

None.

\section{Competing interests}

None.

\section{Availability of data and materials}

Data available upon request.

\section{Consent for publication}

All authors give their consent.

Ethics approval and consent to participate

Not applicable to meta-analysis.

\section{Funding}

None.

\section{Publisher's Note}

Springer Nature remains neutral with regard to jurisdictional claims in published maps and institutional affiliations.

Received: 21 May 2017 Accepted: 18 August 2017

Published online: 30 August 2017

\section{References}

1. Alberti KG, Eckel RH, Grundy SM, Zimmet PZ, Cleeman JI, Donato KA, Fruchart JC, James WP, Loria CM, Smith SC Jr, et al. Harmonizing the metabolic syndrome: a joint interim statement of the international diabetes federation task force on epidemiology and prevention; national heart, lung, and blood institute; American heart association; world heart federation; international atherosclerosis society and international association for the study of obesity. Circulation. 2009:120(16):1640-5.

2. Shin JA, Lee JH, Lim SY, Ha HS, Kwon HS, Park YM, Lee WC, Kang MI, Yim $\mathrm{HW}$, Yoon $\mathrm{KH}$, et al. Metabolic syndrome as a predictor of type 2 diabetes, and its clinical interpretations and usefulness. J Diabetes Investig. 2013:4(4):334-43.

3. Yamaoka K, Tango T. Effects of lifestyle modification on metabolic syndrome: a systematic review and meta-analysis. BMC Med. 2012;10:138.

4. Haqq L, McFarlane J, Dieberg G, Smart N. The effect of lifestyle intervention on body composition, glycemic control, and cardiorespiratory fitness in polycystic ovarian syndrome: a systematic review and meta-analysis. Int J Sport Nutr Exerc Metab. 2015;25(6):533-40.

5. Haqq L, McFarlane J, Dieberg G, Smart N. Effect of lifestyle intervention on the reproductive endocrine profile in women with polycystic ovarian syndrome: a systematic review and meta-analysis. Endocrine connections. 2014;3(1):36-46.

6. Grace A, Chan E, Giallauria F, Graham PL, Smart NA. Clinical outcomes and glycaemic responses to different aerobic exercise training intensities in type II diabetes: a systematic review and meta-analysis. Cardiovasc Diabetol. 2017:16(1):37.

7. Lemes IR, Ferreira PH, Linares SN, Machado AF, Pastre CM, Netto JJ. Resistance training reduces systolic blood pressure in metabolic syndrome: a systematic review and meta-analysis of randomised controlled trials. $\mathrm{Br}$ J Sports Med. 2016. doi:10.1136/bjsports-2015-094715.
8. Aguilera Eguia R, Vergara Miranda C, Quezada Donoso R, Sepulveda Silva M, Coccio N, Cortes P, Delarze C, Flores C. High-intensity interval exercise therapy to reduce cardiovascular risk factors in people with the metabolic syndrome; systematic review with meta-analysis. Nutr Hosp. 2015:32(6):2460-71

9. Lin X, Zhang X, Guo J, Roberts CK, McKenzie S, Wu WC, Liu S, Song Y. Effects of exercise training on cardiorespiratory fitness and biomarkers of cardiometabolic health: a systematic review and meta-analysis of randomized controlled trials. J Am Heart Assoc. 2015;4(7):e002014.

10. Smart NA, Waldron M, Ismail H, Giallauria F, Vigorito C, Cornelissen V, Dieberg $\mathrm{G}$. Validation of a new tool for the assessment of study quality and reporting in exercise training studies: TESTEX. Int J Evid Based Healthc. 2015;13(1):9-18.

11. Higgins JPT, Green S. Cochrane handbook for systematic reviews of interventions. In: version 5.1.0. edn: the Cochrane Library; 2011

12. Higgins JPTTS, Deeks JJ, Altman DG. Measuring inconsistency in metaanalysis. BMJ. 2003;327(7414):557-60.

13. Egger M, Davey Smith G, Schneider M, Minder C. Bias in meta-analysis detected by a simple, graphical test. BMJ. 1997;315(7109):629-34

14. Balducci S, Zanuso S, Nicolucci A, Fernando F, Cavallo S, Cardelli P, Fallucca $\mathrm{S}$, Alessi E, Letizia C, Jimenez A, et al. Anti-inflammatory effect of exercise training in subjects with type 2 diabetes and the metabolic syndrome is dependent on exercise modalities and independent of weight loss. Nutr Metab Cardiovasc Dis. 2010;20(8):608-17.

15. Donley DA, Fournier SB, Reger BL, DeVallance E, Bonner DE, Olfert IM, Frisbee JC, Chantler PD. Aerobic exercise training reduces arterial stiffness in metabolic syndrome. J Appl Physiol. 2014;116(11):1396-404.

16. Irving BA, Davis CK, Brock DW, Weltman JY, Swift D, Barrett EJ, Gaesser GA Weltman A. Effect of exercise training intensity on abdominal visceral fat and body composition. Med Sci Sports Exerc. 2008;40(11):1863-72.

17. Irving BA, Weltman JY, Patrie JT, Davis CK, Brock DW, Swift D, Barrett EJ, Gaesser GA, Weltman A. Effects of exercise training intensity on nocturnal growth hormone secretion in obese adults with the metabolic syndrome. J Clin Endocrinol Metab. 2009;94(6):1979-86.

18. Kim CJ, Kim DJ, Park HR. Effects of a cardiovascular risk reduction intervention with psychobehavioral strategies for Korean adults with type 2 diabetes and metabolic syndrome. J Cardiovasc Nurs. 2011;26(2):117-28.

19. Mager U, Kolehmainen M, de Mello VD, Schwab U, Laaksonen DE, Rauramaa R, Gylling H, Atalay M, Pulkkinen L, Uusitupa M. Expression of ghrelin gene in peripheral blood mononuclear cells and plasma ghrelin concentrations in patients with metabolic syndrome. Eur J Endocrinol. 2008;158(4):499-510

20. Maresca L, D’Agostino M, Castaldo L, Vitelli A, Mancini M, Torella G, Lucci R, Albano G, Del Forno D, Ferro M, et al. Exercise training improves erectile dysfunction (ED) in patients with metabolic syndrome on phosphodiesterase-5 (PDE-5) inhibitors. Monaldi Arch Chest Dis. 2013:80(4):177-83.

21. Oh EG, Bang SY, Hyun SS, Kim SH, Chu SH, Jeon JY, Im JA, Lee MK, Lee JE. Effects of a 6-month lifestyle modification intervention on the cardiometabolic risk factors and health-related qualities of life in women with metabolic syndrome. Metabolism. 2010;59(7):1035-43.

22. Okura T, Nakata Y, Ohkawara K, Numao S, Katayama Y, Matsuo T, Tanaka K. Effects of aerobic exercise on metabolic syndrome improvement in response to weight reduction. Obesity (Silver Spring). 2007;15(10):2478-84

23. Reseland JE, Anderssen SA, Solvoll K, Hjermann I, Urdal P, Holme I, Drevon CA. Effect of long-term changes in diet and exercise on plasma leptin concentrations. Am J Clin Nutr. 2001;73(2):240-5.

24. Sonnenschein $K$, Horvath T, Mueller M, Markowski A, Siegmund T, Jacob $\mathrm{C}$, Drexler $\mathrm{H}$, Landmesser $\mathrm{U}$. Exercise training improves in vivo endothelial repair capacity of early endothelial progenitor cells in subjects with metabolic syndrome. Eur J Cardiovasc Prev Rehabil. 2011;18(3):406-14.

25. Straznicky NE, Lambert EA, Nestel PJ, McGrane MT, Dawood T, Schlaich MP, Masuo K, Eikelis N, de Courten B, Mariani JA, et al. Sympathetic neural adaptation to hypocaloric diet with or without exercise training in obese metabolic syndrome subjects. Diabetes. 2010;59(1):71-9.

26. Soares TS, Piovesan CH, Gustavo Ada S, Macagnan FE, Bodanese LC, Feoli AM. Alimentary habits, physical activity, and Framingham global risk score in metabolic syndrome. Arq Bras Cardiol. 2014;102(4):374-82.

27. AlHW. Impact of overweight and obesity as a risk factor for chronic conditions. Australian burden of disease study series no. 11. Cat. no. BOD 12. Canberra: AlHW; 2017. 
28. Willis LH, Slentz CA, Bateman LA, Shields AT, Piner LW, Bales CW, Houmard JA, Kraus WE. Effects of aerobic and/or resistance training on body mass and fat mass in overweight or obese adults. J Appl Physiol. 2012;113(12):1831-7.

29. Keteyian SJ, Leifer ES, Houston-Miller N, Kraus WE, Brawner CA, O'Connor CM, Whellan DJ, Cooper LS, Fleg JL, Kitzman DW, et al. Relation between volume of exercise and clinical outcomes in patients with heart failure. J Am Coll Cardiol. 2012;60(19):1899-905.

30. Lee DC, Artero EG, Sui X, Blair SN. Mortality trends in the general population: the importance of cardiorespiratory fitness. J Psychopharmacol. 2010:24(4 Suppl):27-35.

31. Sarullo FM, Fazio G, Brusca I, Fasullo S, Paterna S, Licata P, Novo G, Novo S, Di Pasquale P. Cardiopulmonary exercise testing in patients with chronic heart failure: prognostic comparison from peak $\mathrm{VO}_{2}$ and VENCCO2 Slope. Open Cardiovasc Med J. 2010;4:127-34.

32. Parmenter BJ, Dieberg G, Smart NA. Exercise training for management of peripheral arterial disease: a systematic review and meta-analysis. Sports Med. 2015:45(2):231-44.

33. Sietsema KE, Amato A, Adler SG, Brass EP. Exercise capacity as a predictor of survival among ambulatory patients with end-stage renal disease. Kidney Int. 2004;65(2):719-24.

34. Reusch JE, Bridenstine M, Regensteiner JG. Type 2 diabetes mellitus and exercise impairment. Rev Endocr Metab Disord. 2013;14(1):77-86.

35. Cornelissen VA, Buys R, Smart NA. Endurance exercise beneficially affects ambulatory blood pressure: a systematic review and meta-analysis. J Hypertens. 2013;31(4):639-48.

36. Cornelissen VA, Smart NA. Exercise training for blood pressure: a systematic review and meta-analysis. J Am Heart Assoc. 2013;2(1):e004473.

37. Tjonna AE, Lee SJ, Rognmo O, Stolen TO, Bye A, Haram PM, Loennechen JP, Al-Share QY, Skogvoll E, Slordahl SA, et al. Aerobic interval training versus continuous moderate exercise as a treatment for the metabolic syndrome: a pilot study. Circulation. 2008;118(4):346-54.

38. Ismail H, McFarlane JR, Dieberg G, Smart NA. Exercise training program characteristics and magnitude of change in functional capacity of heart failure patients. Int J Cardiol. 2014;171(1):62-5.
39. Ismail H, McFarlane JR, Nojoumian AH, Dieberg G, Smart NA. Clinical outcomes and cardiovascular responses to different exercise training intensities in patients with heart failure: a systematic review and metaanalysis. JACC. 2013;1(6):514-22.

40. Wisloff U, Stoylen A, Loennechen JP, Bruvold M, Rognmo O, Haram PM, Tjonna AE, Helgerud J, Slordahl SA, Lee SJ, et al. Superior cardiovascular effect of aerobic interval training versus moderate continuous training in heart failure patients: a randomized study. Circulation. 2007;115(24):3086-94.

41. Hordern MD, Coombes JS, Cooney LM, Jeffriess L, Prins JB, Marwick TH. Effects of exercise intervention on myocardial function in type 2 diabetes. Heart. 2009;95(16):1343-9.

42. Younis A, Younis A, Tzur B, Peled Y, Shlomo N, Goldenberg I, Fisman EZ, Tenenbaum A, Klempfner R. Metabolic syndrome is independently associated with increased 20-year mortality in patients with stable coronary artery disease. Cardiovasc Diabetol. 2016;15(1):149.

43. Gomez-Marcos MA, Gomez-Sanchez L, Patino-Alonso MC, Recio-Rodriguez Jl, Regalado NG, Ramos R, Marti R, Agudo-Conde C, RodriguezSanchez E, Maderuelo-Fernandez JA, et al. Association between markers of glycemia and carotid intima-media thickness: the MARK study. BMC Cardiovasc Disord. 2016;16(1):203.

44. Gomez-Sanchez L, Garcia-Ortiz L, Patino-Alonso MC, Recio-Rodriguez II, Fernando R, Marti R, Agudo-Conde C, Rodriguez-Sanchez E, MaderueloFernandez JA, Ramos R, et al. Association of metabolic syndrome and its components with arterial stiffness in Caucasian subjects of the MARK study: a cross-sectional trial. Cardiovasc Diabetol. 2016;15(1):148.

45. Fontes-Carvalho R, Ladeiras-Lopes R, Bettencourt P, Leite-Moreira A Azevedo A. Diastolic dysfunction in the diabetic continuum: association with insulin resistance, metabolic syndrome and type 2 diabetes. Cardiovasc Diabetol. 2015;14:4.

\section{Submit your next manuscript to BioMed Central and we will help you at every step:}

- We accept pre-submission inquiries

- Our selector tool helps you to find the most relevant journal

- We provide round the clock customer support

- Convenient online submission

- Thorough peer review

- Inclusion in PubMed and all major indexing services

- Maximum visibility for your research

Submit your manuscript at www.biomedcentral.com/submit
O Biomed Central 